\title{
Temperature Effects on Shoot Growth and Flowering of Kumquat Trees
}

\author{
Yung-Chiung Chang ${ }^{1}$, Iou-Zen Chen ${ }^{2}$, Lian-Hsiung Lin $^{3}$, and Yu-Sen Chang ${ }^{2 *}$ \\ ${ }^{1}$ Department of Horticulture, National Ilan University, No. 1, Sec. 1, Shen-Lung Rd, Ilan 260, Taiwan, ROC \\ ${ }^{2}$ Department of Horticulture and Landscap Architecture, National Taiwan University, No. 1, Sec. 4, Roosevelt Rd. Taipei 106, Taiwan, ROC \\ ${ }^{3}$ Department of Biomechatronic Engineering, National Ilan University, No. 1, Sec. 1, Shen-Lung Rd, Ilan 260,Taiwan, ROC
}

\begin{abstract}
This study investigated the effects of temperature on the shoot growth and flowering of potted kumquat [Fortunella margarita (Lour.) Swingle] trees grown in subtropical conditions of I-Lan County in Taiwan. Temperature treatments included $\mathrm{T} 25-32$, T $17-25$, T 22 , and $\mathrm{T} 18$. The $\mathrm{T} 25-32$ treatment trees were to the day/night temperatures of $25 / 18^{\circ} \mathrm{C}$ for 2 weeks, followed by 28 weeks at $32 / 25^{\circ} \mathrm{C}$. T $17-25$ was exposed for 4 weeks to $17 / 10^{\circ} \mathrm{C}$ followed by 26 weeks at $25 / 18^{\circ} \mathrm{C}$. T 22 and $\mathrm{T} 18$ were exposed at $22 / 18^{\circ} \mathrm{C}$ and $18 / 13^{\circ} \mathrm{C}$, respectively, for the entire duration of the experiment. Control trees were placed in a plastic greenhouse under conditions similar to the natural environment. The kumquat trees exposed to high-temperature environment of $32 / 25^{\circ} \mathrm{C}$ showed more frequent and speedy sprouting of new buds, but induced the earlier termination of shoot elongation growth, resulting in decreased vegetative growth. The temperature treatments lower than $22^{\circ} \mathrm{C}$ suppressed the new shoot production but increased the shoot growth period, resulting in increased shoot length and diameter. Temperatures higher than $25 / 18^{\circ} \mathrm{C}$ readily induced flowering, with flowering being advanced under the higher temperature conditions such as $32 / 25^{\circ} \mathrm{C}$ However, flowering was substantially inhibited under temperature conditions lower than $22 / 18^{\circ} \mathrm{C}$, indicating the negative role of relatively lower temperatures on flowering of kumquat trees.
\end{abstract}

Additional key words: bud sprouting, flowering potential, flush sequence, shoot growth, small-fruited citrus

\section{Introduction}

Kumquat (Fortunella spp.) is an evergreen shrub or small tree of the genus Fortunella in the family Rutaceae, and its orange-yellow fruits are the smallest edible citrus fruits (Ying, 1998). Kumquat trees may flourish in hot countries and subtropical regions, but have the capability to tolerate freezing and subfreezing periods (Manner et al., 2006). Kumquat fruits provide health benefits to people through immune system enhancement (Kondo et al., 2005). The $\cdot \mathrm{OH}$ scavenging capacity of freeze-dried peel extract of kumquat is higher than that of scavenging $\mathrm{O}_{2} .^{-}$(Chen et al., 2010).

In most subtropical areas, low temperatures are an essential factor for citrus flowering (Albrigo and Saúco, 2004; Davenport, 1990). Moss (1969) demonstrated with sweet orange under temperature treatments from $15^{\circ} \mathrm{C}$ to $27^{\circ} \mathrm{C}$ that lower temperatures improved flower production more than higher temperatures did. Furthermore, the number of mixed or flower buds shifted from lateral vegetative buds was increased as low-temperature durations increased. In contrast, higher temperatures increased the possibility of vegetative growth in shoots (Moss, 1969). Southwick and Davenport (1986) indicated that the low temperature of $18 / 10^{\circ} \mathrm{C}$ induced a time-dependent flowering response in 'Tahiti' lime. In 'Valencia' and 'Hamlin' oranges, a greater accumulation of hours at temperatures of $11^{\circ} \mathrm{C}$ to $15^{\circ} \mathrm{C}$ increased floral intensity in terms of the number of sprouting buds with reproductive growth and the number of flowers per flowering bud (Valiente and Albrigo, 2004).

The sprouting season of shoots also influences the lowtemperature sensitivity of citrus shoots. A seasonal change in bud competence was reported in some citrus cultivars

\footnotetext{
*Comesponding author: yschang@ntu.edu.tw

※ Received 25 September 2012; Revised 9 October 2013; Accepted 7 November 2013. We would like to express our thanks to the Council of Agriculture, Taiwan for funding the projects. We would like to thank T. C. Lin, a student at National Ilan University, who kindly provided assistance with the project.

(C) 2014 Korean Society for Horticultural Science
} 
such as 'Bearss' lime (Citrus latifolia Tan.), 'Fino' lemon [C. limon (L.) Burm. f.], and 'Owari' satsuma [C. unshiu (Mak.) Marc.], with the highest bud sprouting and flower formation exhibited together when a low-temperature regime $\left(15 / 8^{\circ} \mathrm{C}\right)$ was imposed during February and March. During the summer season, a low-temperature regime resulted in a small increase in bud sprouting compared to non-chilled trees, even though only vegetative buds were developed and no flowers were formed (Nebauer et al., 2006).

In the subtropics, large-fruited citrus species usually exhibit flush growth twice throughout the year, and flowering is concentrated in spring flushes (Davenport, 1990; Monselise 1985). Multiple shoot sprouting occurs frequently in smallfruited citrus species; for example, kumquat and calamondin in Japan and Taiwan express 3 to 5 flushes a year (Chang et al., 2009; Iwahori and Tominaga, 1986; Lai and Chen, 2007), and flowering may be found on nearly every flush sequence throughout the year. This implies that low temperatures may not play a critical role in the flowering of small-fruited citrus. Lai and Chen (2008) reported that the calamondin trees placed in $20 / 15^{\circ} \mathrm{C}$ and $15 / 13^{\circ} \mathrm{C}$ environments for 14 weeks failed to bloom, whereas 2 weeks after the trees were moved to $32 / 25^{\circ} \mathrm{C}$, flower buds were formed. This result indicates that low temperatures may restrain the flowering of calamondin. There have been far fewer studies on the small-fruited citrus species than on the large-fruited citrus species. Therefore, the aim of this study was to discover whether low temperature is a necessary factor in inducing flowering of kumquat. On the basis of the hypothesis that the extent of shoot growth and flowering is moderated by the temperature during whole growing season.

\section{Material and Methods}

\section{Plant Material and Experimental Design}

This study used one-hundred potted 2-year-old kumquat trees [Fortunella margarita (Lour.) Swingle] grafted onto trifoliate [Poncirus trifoliata (L.) Raf.] rootstocks. The trees were planted in $8 \mathrm{~L}$ plastic containers filled with a mixture of loam, sand, peat, and cocomoss fiber (2:4:1:1 by volume), and were kept in a plastic greenhouse at National Ilan University, I-Lan County, in Northeastern Taiwan $\left(23.5^{\circ} \mathrm{N}\right.$, $\left.120.3^{\circ} \mathrm{E}\right)$. The greenhouse $(12 \mathrm{~m} \mathrm{~L} \times 7 \mathrm{~m} \mathrm{~W} \times 4 \mathrm{~m} \mathrm{H})$ was constructed of aluminum frame and covered with clear, transparent polyethylene film that can transmit about $87 \%$ of solar photosynthetic photon flux density (PPFD). No supplemental lights were used. Outdoor light levels varied across a year from $600 \mu \mathrm{mol} \cdot \mathrm{m}^{-2} \cdot \mathrm{s}^{-1} \mathrm{PPFD}$ in winter to
$1000 \mu \mathrm{mol} \cdot \mathrm{m}^{-2} \cdot \mathrm{s}^{-1}$ in summer. The polyethylene film was vaulted covered on the roof. To improve the airflow in greenhouse, the greenhouse was equipped with immovable nets at the frontage and backside; and two side roll-up vents located $0.6 \mathrm{~m}$ from the ground with a maximum opening of $1.5 \mathrm{~m}$. Besides, four electric fans worked to maintain homogeneity of microclimate variables inside the greenhouse and avoided heat trapped during summer. The field capacity and wilting point of the substrate were nearly $40 \%$ and 25\% (wt/wt), respectively. During the experimental period, pot soil moisture was maintained at levels near the field capacity. After harvest in January 2010, all trees were moderately pruned to induce the sprouting of new buds through the period of mid February to March. Daily air temperatures were recorded by an automatic weather recorder (EL-USB-2-RH/Temperature Data Logger, Lascar Electronics LTD., UK) located in the greenhouse (Fig. 1).

Temperature treatments were made in the plastic greenhouse and growth chambers (ST4-W3D, SAINT TIEN CO., Ltd., Taiwan). Light intensity in the growth chamber was maintained at an average PPFD of $500 \mu \mathrm{mol} \cdot \mathrm{m}^{-2} \cdot \mathrm{s}^{-1}$. On March 18, 2010, six uniform trees per temperature treatment were selected. Five temperature treatments were designed as follows: T 25-32, T 17-25, T 22, T 18, and control (Fig 2). For the $T$ 25-32 treatment, trees stayed in the greenhouse for the first 6 weeks, then in a growth chamber with day/ night temperatures of $25 / 18^{\circ} \mathrm{C}$ for two weeks and finally in a growth chamber with day/night temperatures of $32 / 25^{\circ} \mathrm{C}$ for 28 weeks. Trees in the T 17-25 group stayed in the greenhouse for the first 6 weeks, then in a growth chamber

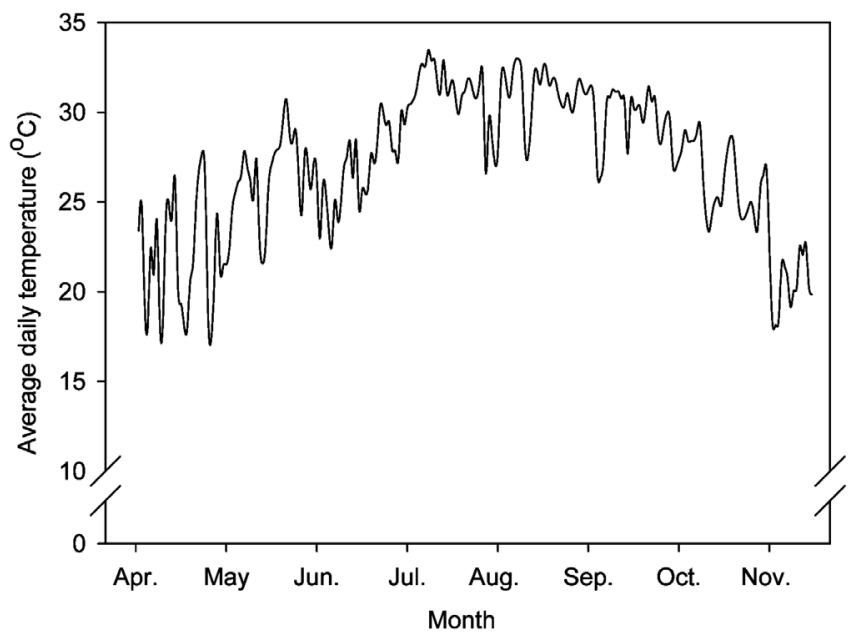

Fig. 1. Variations in the daily mean air temperatures in a plastic greenhouse conditions during the experimental period in 2010. 


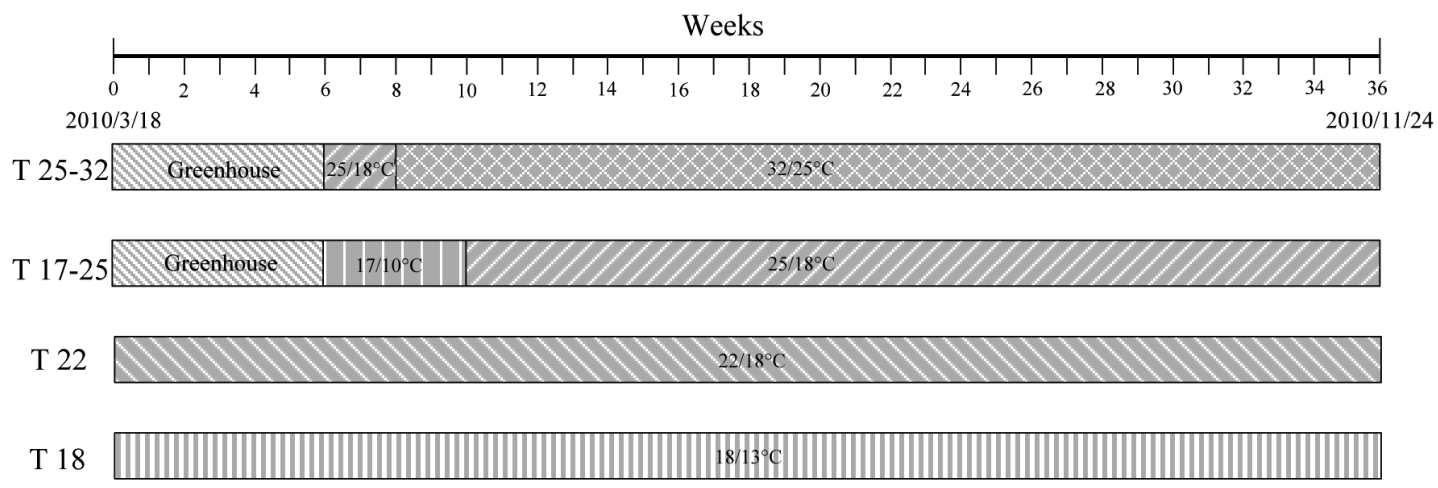

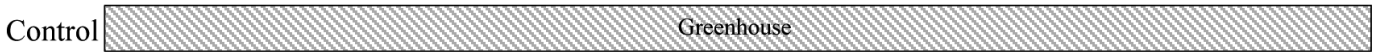

Fig. 2. Temperature treatment programs. For $\mathrm{T} 25-32$, trees were placed in $25 / 18^{\circ} \mathrm{C}$ at the $6^{\text {th }}$ week and transferred to $32 / 25^{\circ} \mathrm{C}$ two weeks later. For $\mathrm{T} 17-25$, trees were placed in $17 / 10^{\circ} \mathrm{C}$ at the $6^{\text {th }}$ week and transferred to $25 / 18^{\circ} \mathrm{C}$ four weeks later. For $\mathrm{T} 22$ and $\mathrm{T} 18$, trees were continuously grown at $22 / 18^{\circ} \mathrm{C}$ and $18 / 13^{\circ} \mathrm{C}$, respectively. Control trees were grown in a plastic greenhouse.

with day/night temperatures of $17 / 10^{\circ} \mathrm{C}$ for four weeks and finally in a growth chamber at $25 / 18^{\circ} \mathrm{C}$ for 26 weeks. For T 22 and T 18 treatments, trees were placed in growth chambers with day/night temperatures of $22 / 18^{\circ} \mathrm{C}$ and $18 / 13^{\circ} \mathrm{C}$, respectively, throughout the entire period of the experiment. To diminish environmental interference caused by rainfall or other factors, the control group was placed in the plastic greenhouse.

\section{Shoot Growth and Flowering Measurements}

Six kumquat trees were selected for each treatment, and 10 uniform newly-sprouted shoots (the first flushes) were labeled per tree. Because of kumquat's multiple flushes sprouting behavior, different flush sequences were analyzed independently. Flush sequence was defined as the order of bud appearance in a year. The first flush was made up of the shoots first sprouted in the spring, and the second flush was made up of shoots sprouted onto the first flush, and so on (Fig. 3). The sprouting timing of a flush sequence was determined when newly developed shoots of the same sequence were observed in at least half of the sampled trees. The growth and flowering of shoots were examined throughout the experiment. The number of buds sprouted and the shoot growth (length and diameter) were recorded biweekly. The extent of flowering was determined as the number of flowers per shoot for each flush, and the rate of flowering nodes to total nodes in each shoot was measured as the flowering rate of shoot. At the end of the experiment, the total number of flowers per tree was also counted.

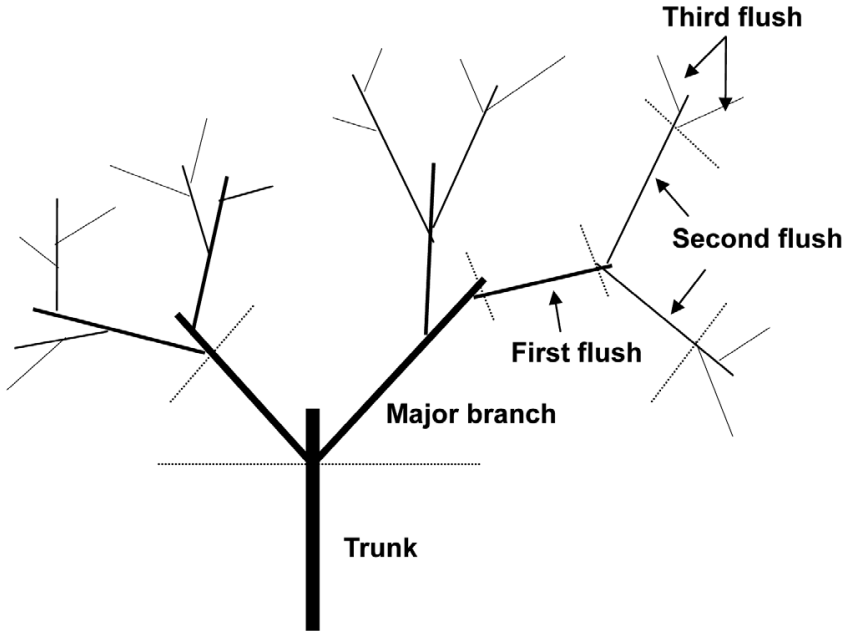

Fig. 3. Growth pattern of kumquat [Fortunella margarita (Lour.) Swingle] trees.

\section{Statistical Analyses}

The experiment was performed in a complete randomized design. The data were analyzed using the SAS program (Statistical Analysis System V8, SAS Institute, USA) for an analysis of variance (ANOVA), followed by the least significant difference (LSD) test to evaluate significant differences between treatments.

\section{Results}

\section{Effects of Temperature on New Bud Sprouting and Shoot} Growth

The number of buds sprouted exhibited significant variations 
Table 1. Effects of growth temperatures on the number and timing of bud sprouting in different kumquat flush sequences. For the description of treatments, see Fig. 2.

\begin{tabular}{|c|c|c|c|c|c|c|c|c|}
\hline \multirow{2}{*}{ Treatment } & \multicolumn{4}{|c|}{ Average number of buds sprouted per first flush shoot } & \multicolumn{4}{|c|}{ Time of bud sprouting (weeks since March 18 , and date) } \\
\hline & Second flush & Third flush & Fourth flush & Fifth flush & Second flush & Third flush & Fourth flush & Fifth flush \\
\hline Control & $1.70^{\mathrm{z}} \mathrm{a}^{\mathrm{y}}$ & $0.72 \mathrm{a}$ & $0.16 \mathrm{ab}$ & $0.14 \mathrm{a}$ & 10/May 27 & 16/Jul. 7 & 28/Sep. 30 & 32/Oct. 27 \\
\hline T $25-32$ & $1.62 \mathrm{ab}$ & $0.85 \mathrm{a}$ & $0.34 \mathrm{a}$ & $0.11 \mathrm{a}$ & 8/May 13 & 16/Jul. 7 & 24/Sep. 2 & 30/Oct. 13 \\
\hline T $17-25$ & $0.68 \mathrm{bc}$ & $0.59 \mathrm{a}$ & $0.00 \mathrm{~b}$ & $0.00 \mathrm{a}$ & 14/Jun. 23 & 32/Oct. 27 & - & - \\
\hline Т 22 & $0.46 \mathrm{c}$ & $0.00 \mathrm{a}$ & $0.00 \mathrm{~b}$ & $0.00 \mathrm{a}$ & 20/Aug. 4 & - & - & - \\
\hline Т 18 & $0.00 \mathrm{c}$ & $0.00 \mathrm{a}$ & $0.00 \mathrm{~b}$ & $0.00 \mathrm{a}$ & $-{ }^{\mathrm{x}}$ & - & - & - \\
\hline
\end{tabular}

${ }^{\mathrm{z}}$ The data are means of six trees.

${ }^{\mathrm{y}}$ Mean values within each column followed by a different letter are significantly different at $p \leq 0.05$ by LSD.

${ }^{\mathrm{x}}$ No new shoot sprouting was observed.

among the treatment groups and flush sequences (Table 1). The $\mathrm{T} 25-32$ group sprouted their second flush buds after transfer to $32 / 25^{\circ} \mathrm{C}$ for 2 weeks and these results were similar to those of the control group but significantly different from $\mathrm{T} 17-25, \mathrm{~T} 22$, and $\mathrm{T} 18$. However, the trees kept at lower temperatures such as $22 / 18^{\circ} \mathrm{C}$ and $17 / 13^{\circ} \mathrm{C}$ showed a reduced bud sprouting; the $\mathrm{T} 22$ trees only sprouted the second flush buds, whereas the T 18 trees could not sprout any new buds after the first flush. Bud sprouting of the fourth and fifth flushes was recorded only in the control and $\mathrm{T}$ 25-32 groups. The trees placed in a natural environment expressed a fluctuation in bud sprouting; however, more stable results appeared in the temperaturecontrolled groups (Table 1).

The shoot growth of the second flush in the T 25-32 group was terminated after 2 weeks of bud sprouting, and the average shoot length was the shortest among all the treatments. The T 22 trees, placed in a growth chamber at the beginning of the experiment, showed a longer period of the first flush shoot elongation growth than those in the higher-temperature treatments. In the $\mathrm{T} 18$, the shoot elongation of the first flush was terminated after trees were exposed to $18 / 10^{\circ} \mathrm{C}$ for 6 weeks, and the trees eventually died at the 18th week. Unlike the trees placed in the growth chambers, those in the greenhouse showed more obvious variations in shoot length among different flush sequences, Shoot diameters of the greenhouse trees increased as the treatment period increased, and shoot diameters did not exhibit the obvious termination stage that shoot length did. Because the trees in the T 25-32 and T 17-25 groups were moved to the growth chambers when the shoot elongation of the first flush was nearly completed, shoot diameters of the first flush in both treatments exhibited similar diameter variation trends as the second flush of the control group, where temperatures averaged from 25 to $32^{\circ} \mathrm{C}$. The temperature of T 25-32 group's second, third, and fourth flushes emerged was $32 / 25^{\circ} \mathrm{C}$ and their shoot diameter growth variations similar to the control group's third flush which grew during the high temperatures of summer. Trees in the T 22 group showed a shoot diameter variation comparable to that of the first flush of the control group. The $\mathrm{T} 18$ trees at $18 / 13^{\circ} \mathrm{C}$ showed obviously weaker growth than those in other temperature treatments (Fig. 4).

\section{Effects on Flowering}

Fig. 5 shows a pattern of repeated flowering in kumquat. The flowering rate of shoot and flower number per shoot were higher in the $\mathrm{T}$ 25-32 group than in other temperature groups. Flowering potential was decreased as flush sequences increased. In T25-32, the first peak of flowering rate was $100 \%$, occurring after trees had been exposed to $32 / 25^{\circ} \mathrm{C}$ for 2 weeks, and each shoot of the first flush had an average of 20 flowers. The second flowering peak, with a flowering rate of $95 \%$, was recorded at the 14th week. At the 17 th, 23th, and 34th weeks, shoots of the first flush of the T 25-32 group still had flowering rate peaks of nearly $50 \%$. Shoots of the second flush of the T 25-32 group expressed a weaker flowering potential than those of the first flush. This situation extended to the results of the third flush, which expressed the worst flowering potential in the $\mathrm{T}$ 25-32 group. The shoots on the first flush of the control group reached a flowering peak of $68 \%$ in late May, with an average of 6 flowers blooming per shoot. The second flush shoots in the control group approached a 50\% flowering rate in the middle of August and early September, but showed fewer flowers in both peaks. Shoots of the first flush in the T 17-25 group only exhibited a peak of $56 \%$ flowering rate after the trees had been exposed to $25 / 17^{\circ} \mathrm{C}$ for 4 


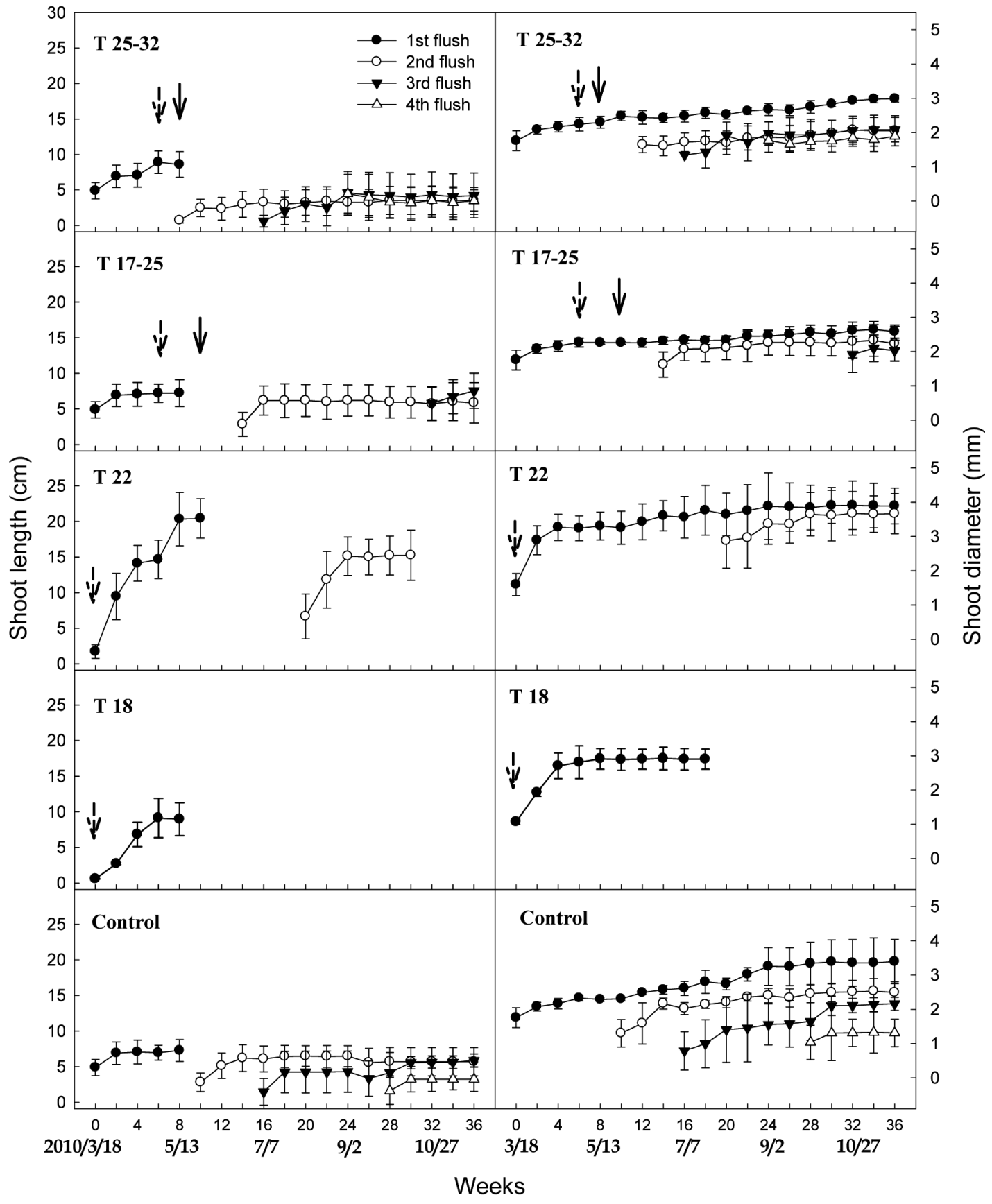

Fig. 4. Effect of temperatures on shoot growth of kumquat trees. For the description of treatments, see Fig. 2. Dash and solid arrows indicate when trees were moved to the growth chamber and when the temperature was changed, respectively. Each value represents the mean \pm S.E. $(n=6)$.

weeks. The flowering potential of shoots in the $\mathrm{T} 17-25$ group was generally inferior to that of the other treatment groups (Fig. 5). The trees grown in the temperatures lower than $22^{\circ} \mathrm{C}$ were unable to flower as regularly as those in control, T 25-32 and T 17-25 groups (data not shown). Flowering inhibition was distinctly shown in the T 22 and
T 18 groups. The total flower numbers of shoots of the first flush were significantly higher in the $\mathrm{T}$ 25-32 group than in the other treatment groups. The total flower numbers of shoots of the second and third flushes of the T 25-32 group exhibited no significant differences from those of the control group, but were significantly different from those 


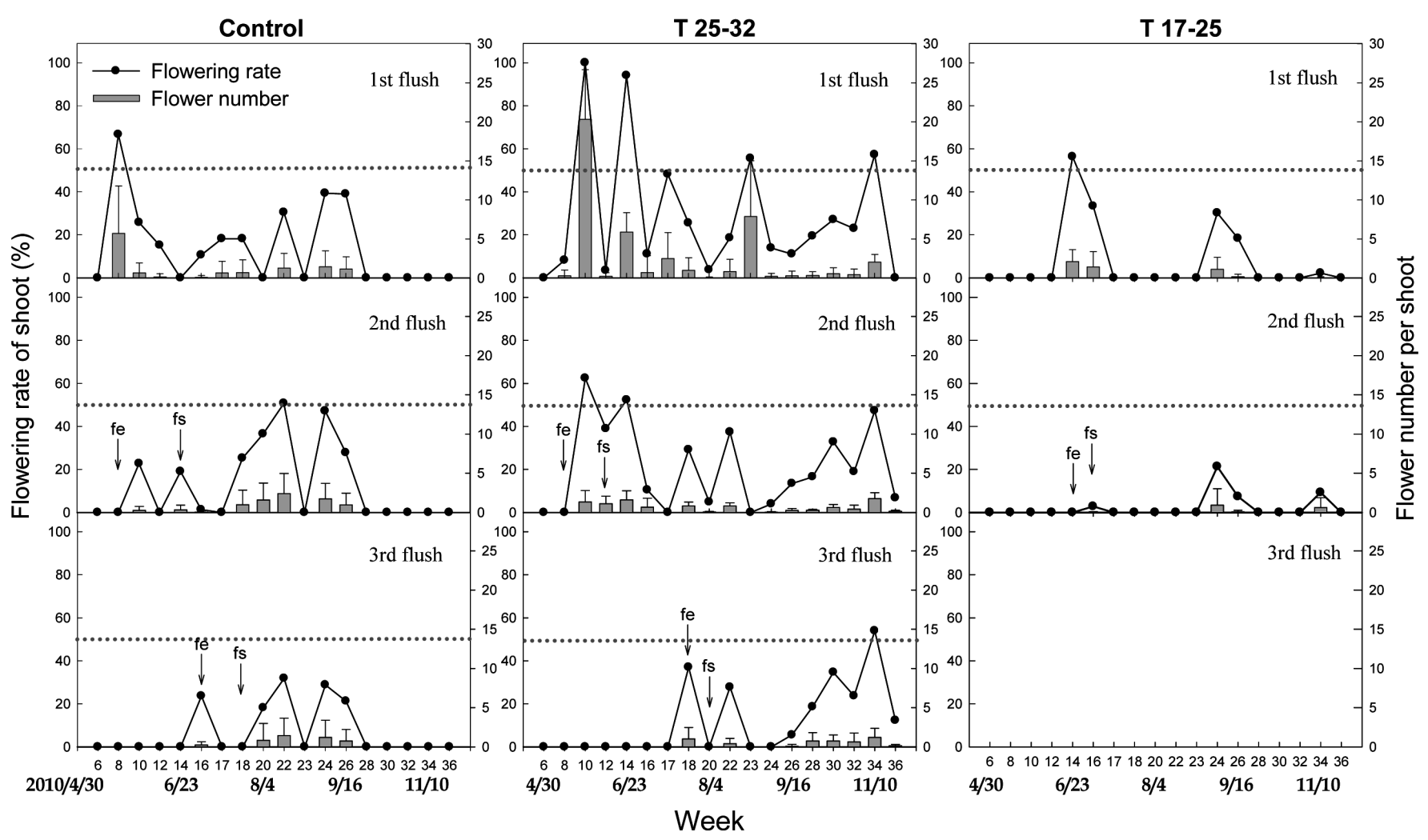

Fig. 5. Effect of different temperatures on flowering rate and flower number of the first, second, and third flushes of kumquat trees. For the description of treatments, see Fig. 2. fe and fs indicate shoot emergence and termination of shoot elongation growth, respectively. Each value represents the mean \pm S.E. $(n=6)$.

of the $\mathrm{T}$ 17-25, T22, and T18 groups (Fig. 6).

\section{Discussion}

Temperature variations in the control group ranged from $22^{\circ} \mathrm{C}$ to $28^{\circ} \mathrm{C}$ from the beginning of the experiment to the 14th week. Average recorded temperatures in the greenhouse were higher than $30^{\circ} \mathrm{C}$ during the period from the 14 th to the 24th week, and then remained lower than $25^{\circ} \mathrm{C}$ after the 24th week (Fig. 1). Shoot growth was inversely proportional to flush sequences; therefore, shoot vigor was highest in the first flush and lowest in the fourth flush. Trees in the $\mathrm{T}$ 25-32 group produced a considerable number of new shoots, but exhibited a shorter period of shoot growth. Because of the similar temperature conditions, vegetative growth of T 25-32 shoots resembled that of the shoots of the third and fourth flushes of the control group. The results of the $\mathrm{T}$ 17-25 group indicated that temperatures lower than $32 / 25^{\circ} \mathrm{C}$ decreased shoot numbers but prolonged the shoot extension period and extended the diameter of the shoots. Bud sprouting and shoot growth was suppressed by temperatures lower than $22 / 18^{\circ} \mathrm{C}$. Trees in $\mathrm{T} 18$ displayed feeble growth and inhibited bud sprouting, and these trees eventually died at the 18th week (Fig. 4).

Most citrus trees sprout two flushes per year in subtropical regions (Davenport, 1990; Monselise, 1985); moreover, citrus flowers form on buds of the previous summer's shoot and bloom in spring following the winter cold period (Iwahori et al., 1990). Midsummer and subsequent shoots are usually much smaller, and only vegetative shoots develop. In tropical climates, bud sprouting may occur without interruption throughout the year (Monselise, 1985; Spiegel-Roy and Goldschmidt, 1996). At temperatures over $32^{\circ} \mathrm{C}$, which are typical of summer or early fall in Taiwan and are similar to the temperatures of tropical climates, kumquats also express uninterrupted bud sprouting characteristics. The shoots formed at higher temperatures are smaller than those formed at lower temperatures. In contrast, kumquat shoots which sprout in the spring in Taiwan, when average temperatures are between $22^{\circ} \mathrm{C}$ and $28^{\circ} \mathrm{C}$, have a sufficient growth period to ensure adequate flower and fruit production. Similar results have also been reported for 'Meiwa' kumquat; 

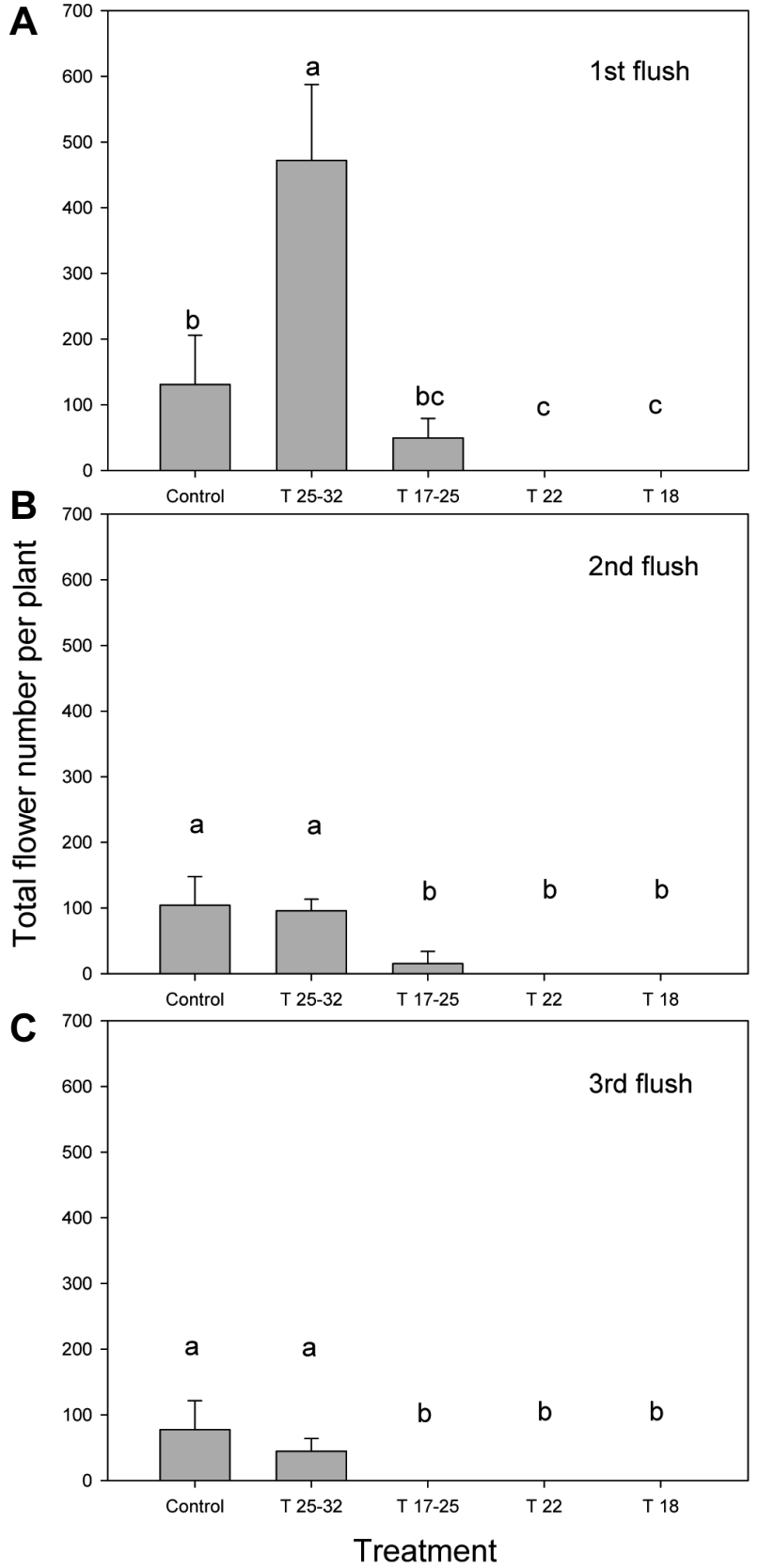

Fig. 6. Effect of growth temperatures on the number of total flowers per kumquat tree set on (A) the first flushes, (B) the second flushes, and (C) the third flushes. For the description of treatments, see Fig. 2. Each value represents the mean \pm S.E. $(n=6)$.

fruit from the first flowering shoot was largest and of the highest quality (Iwahori and Tominaga, 1986). Low temperatures are a critical factor in flower bud induction in subtropical zones. In large-fruited citrus trees, temperatures lower than $20^{\circ} \mathrm{C}$ result in bud inactivity, and additional cool weather at these temperatures induces buds to become flower buds
(Moss, 1969; Reuther et al., 1973). As the hours at temperature of $15^{\circ} \mathrm{C}$ increase, the type of mixed to generative buds of sweet orange increases, but if the temperature is close to $27^{\circ} \mathrm{C}$, only vegetative buds form (Moss, 1969; Valiente and Albrigo, 2004). The flowering rate of lime can exceed $50 \%$ if a low temperature of $18 / 10^{\circ} \mathrm{C}$ is sustained for 4 weeks (Southwich and Davenport, 1986).

Small-fruited citrus kumquat trees display a flowering pattern markedly different from large-fruited citrus species. Higher temperature make shoots flower abundantly. The first flush shoots of kumquat initiated flowering after 2 weeks at $25 / 18^{\circ} \mathrm{C}$ and full blooming occurred when trees were exposed to $32 / 25^{\circ} \mathrm{C}$ for 2 weeks (Fig. 5). Moreover, shoots sprouted and grew in $32 / 25^{\circ} \mathrm{C}$; for example, the second and third flushes of $\mathrm{T}$ 25-32 expressed vigorous flowering potential as well. In contrast to shoots grown at lower temperatures, shoots grown at $17 / 10^{\circ} \mathrm{C}$ for 4 weeks did not flower, but reached a flowering rate exceeding $50 \%$ after growing at $25 / 18^{\circ} \mathrm{C}$ for 4 weeks. To distinguish whether or not lower temperatures are required to induce floral initiation of kumquat's shoots, trees were continuously grown at $22 / 18^{\circ} \mathrm{C}$ and $18 / 13^{\circ} \mathrm{C}$. The results show that the shoots which were sprouted and grown under $22 / 18^{\circ} \mathrm{C}$ were unable to flower. The above-mentioned aspects indicate that low temperatures may not directly affect the flowering potential of kumquat shoots.

The characteristics of kumquat bud sprouting are apparently different from those of sweet orange, which sprout more vegetative buds at higher temperatures than at lower temperatures (Moss, 1969). The buds on the second flush in the T 25-32 group were sprouted after 2 weeks of increased temperatures to $32 / 25^{\circ} \mathrm{C}$ and achieved a flowering rate of $60 \%$, indicating that kumquats under a high temperature regime of $32 / 25^{\circ} \mathrm{C}$ produce not only vegetative shoots but also reproductive ones. In the control group, shoot elongation growth on the second and third flushes, in which the buds were sprouted in summer and autumn, respectively, was obviously smaller than that on the first flush. The shoot lengths of the second and third flushes sprouted at $32 / 25^{\circ} \mathrm{C}$ were shorter because the shoot expansion periods were shorter. This decline in shoot length might have diminished the carbohydrate accumulation in shoots, substantially reducing the number of flowers. Early fruit removal and branch girdling caused an accumulation of carbohydrates in the leaves and increased flower formation in satsuma mandarin (Citrus unshiu Marc.) trees (Garcia-Luis et al., 1995). Hence, the positive effects of low temperature on large-fruited citrus flowering might be caused by vegetative growth inhibition, which promotes carbohydrate accumulation in shoots and 
profits flowering. In kumquat, as in most citrus species, flower initiation follows the termination of shoot elongation (Chang et al., 2009). However, high temperatures of $32 / 25^{\circ} \mathrm{C}$ increased the mixed bud sprouting rate of the shoot apex, and resulted in shorter shoot length and flower nodes, decreasing the number of flowers. In brief, the positive effects of low temperature on large-fruited citrus flowering are caused by carbohydrate accumulation in shoots and might not be relevant to kumquats. A probable inference is that the carbohydrate requirement for small-fruited citrus flowering may not only be provided by the newly-sprouted shoots, but may also be supplied by branches that are 2 or more years old. Therefore, kumquat requires a sufficiently high temperature $\left(>25^{\circ} \mathrm{C}\right)$ for flowering, regardless of the age and length of shoots.

The inhibiting effects of low temperatures on flowering of kumquat trees are similarly observed in calamondin trees (Lai and Chen, 2007). In a natural environment, kumquats sprouted their first and second flushes buds from spring to early summer, when average temperatures seldom exceeded $28^{\circ} \mathrm{C}$. Therefore, shoots in a natural environment have a longer expansion period to accumulate enough carbohydrates for vegetative and reproductive growth. The third flush buds were sprouted in July, when temperatures usually exceeded $32^{\circ} \mathrm{C}$. These shoots matured prematurely, resulting in decreased shoot length and flowering potential. The fourth flush buds sprouted in September, when daytime temperatures exceeded $32^{\circ} \mathrm{C}$. The shoots on the fourth flush expressed poor growth and scanty flowering, indicating that these shoots could be not useful for production. Although high temperatures $\left(>25^{\circ} \mathrm{C}\right)$ promote kumquat flowering, temperatures above $32^{\circ} \mathrm{C}$ decrease shoot growth and encourage frequent flowering that wastes shoot nutrients and decreases fruit production (Goldschmidt et al., 1985). Calamondin trees placed at $30 / 25^{\circ} \mathrm{C}, 25 / 20^{\circ} \mathrm{C}, 20 / 15^{\circ} \mathrm{C}$, and $15 / 13^{\circ} \mathrm{C}$ flowered for $2,8,22$, and 22 weeks, respectively (Lai and Chen, 2008). In other words, although calamondin flowered more slowly at lower temperatures than at higher temperatures, lower temperatures did not thoroughly suppress calamondin flowering (Lai and Chen, 2008). However, kumquat could not flower at temperatures lower than $22 / 18^{\circ} \mathrm{C}$, indicating that flowering in kumquat trees is more temperaturedependent than in calamondin trees, although lower temperatures may have similar negative effects on shoot development and flowering in both kumquat and calamondin.

Kumquat trees show multiple sprouting flushes and bloom repeatedly during a growth period. In this study, the trees that were grown at $25 / 18^{\circ} \mathrm{C}$ and then transferred to $32 / 25^{\circ} \mathrm{C}$ showed the most frequent bud sprouting, but had the least vegetative growth potential. Conversely, temperatures lower than $22 / 18^{\circ} \mathrm{C}$ suppressed the sprouting of new kumquat buds but increased both shoot extension growth period and the length and diameter of the newly-sprouted shoots. Once shoot elongation had terminated, flowering occurred only under temperatures higher than $25 / 18^{\circ} \mathrm{C}$, no matter what season the kumquat shoots were sprouted. These results indicate that even if most of large-fruited citrus trees require low temperature for flowering, low temperature is not an essential requirement for the flowering of kumquat. A further study on anatomical examination of the buds could be required to better clarify whether low temperature caused a failure of flower bud formation or induced the floral bud differentiation but inhibited further development of the floral buds. This study demonstrated the effects of temperature on the shoot growth and flowering of kumquat trees, and might provide a practical strategy for flush management that regulates flowering and fruiting of kumquat trees.

\section{Literature Cited}

Albrigo, L.G. and V.G. Saúco. 2004. Flower bud induction, flowering and fruit-set of some tropical and subtropical fruit tree crops with special reference to citrus. Acta Hort. 632:81-90.

Chang, Y.C., H.C. Yu, J.H. Xie, I.Z. Chen, and Y.S. Chang. 2009. Investigation of growth and flower phenology on kumquat. Conf. Taiwan Soc. Hort. Sci. 55:295. (Abstr.)

Chen, R.Y., J.P. Huang, and M.J. Tsai. 2010. The effect of the kumquat (Fortunella margarita Swingle) peel extract on the inflammatory biomarkers associated with cardiovascular risk. Taiwanese J. Agric. Chem. Food Sci. 48:112-119.

Davenport, T.L. 1990. Citrus flowering. Hort. Rev. 12:349-408.

Garcia-Luis, A, F. Fornes, and J.L Guardiola. 1995. Leaf carbohydrates and flower formation in citrus. J. Amer. Soc. Hort. Sci. 120: 222-227.

Goldschmidt, E.E., N. Aschkenazi, Y. Herzano, A.A. Schaffer, and S.P. Monselise. 1985. A role for carbohydrate levels in the control of flowering in citrus. Sci. Hort. 26:159-166.

Iwahori, S., A. Garcia-Luis, P. Santamarina, C. Monerri and J.L. Guardiola. 1990. The influence of ringing on bud development and flowering in satsuma mandarin. J. Exp. Bot. 41:1341-1346.

Iwahori, S. and S. Tominaga. 1986. Increase in first-flush flowering of 'Meiwa' kumquat, Fortunella crassifolia Swingle, trees by paclobutrazol. Sci. Hort. 28:347-353.

Kondo S., R. Katayama, and K. Uchino. 2005. Antioxidant activity in meiwa kumquat as affected by environmental and growing factors. Environ. Exp. Bot. 54:60-68.

Lai, Y.T. and I.Z. Chen. 2007. Effect of heavy pruning on calamondin (Citrus microcarpa) flower bud formation and flowering. J. Taiwan Soc. Hort. Sci. 55:185-194. 
Lai, Y.T. and I.Z. Chen. 2008. Effect of temperature on calamondin (Citrus microcarpa) flowering and flower bud formation. Acta Hort. 773:111-116.

Manner, H.I., R.S. Buker, V.E. Smith, and C.R. Elevitch. 2006. Citrus species (citrus), ver. 2.1. In: C.R. Elevitch. (ed.). Species profiles for Pacific island agroforestry. Permanent Agriculture Resources (PAR), Hōlualoa, Hawaii. http://www.traditionaltree. org.

Monselise, S.P. 1985. Citrus and related genera, Vol. 2, p. 275-294. In: A.H. Halevy (ed.). Handbook of flowering. CRC Press, Boca Raton, Fla.

Moss, G.I. 1969. Influence of temperature and photoperiod on flower induction and inflorescence development in sweet orange (Citrus sinesis L. Osbeck). J. Hort. Sci. 44:311-320.

Nebauer, S.G., C. Avila, A. García-Luis, and J.L. Guardiola. 2006. Seasonal variation in the competence of the buds of three cultivars from different citrus species to flower. Trees 20:
507-514.

Reuther, W., E.M. Nauer, and L. Summers. 1973. Effects of seasonal temperature regimes on development and maturation of citrus fruits. Proc. Int. Soc. Citriculture 3:63-71.

Southwick, S.M. and T.L. Davenport. 1986. Characterization of water stress and low temperature effects of flower induction in citrus. Tree Physiol. 81:26-29.

Spiegel-Roy P. and E.E. Goldschmidt. 1996. The vegetative citrus trees: Development and function, p. 47-69. In: Biology of citrus. Cambridge University Press, NY, USA.

Valiente, J.I. and L.G. Albrigo. 2004. Flower bud induction of sweet orange trees (Citrus sinesis (L.) Osbeck): Effect of low temperatures, crop load, and bud age. J. Amer. Soc. Hort. Sci. 129:158-164.

Ying, S.S. 1998. Coloured Illustrated Flora of Taiwan, Vol. 6. Shao-Shun Ying Publish, Taipei, Taiwan. p. 65-135. 